\title{
Principales tendencias en el VínCUlo EdUCACión Y EMPleo: los Jóvenes en la Argentina \\ DE LA POSTCONVERTIBILIDAD (2004-2014)
}

\author{
Main Trends in the Link Between Education \\ and Employment: Young People in Argentina \\ of the Post Convertibility Period (2004-2014)
}

\section{María Berenice Rubio ${ }^{*}$ María Noel Fachal ${ }^{* * *}$}

Resumen: En el presente escrito se abordará la relación que asume la educación formal, la inserción laboral y los ingresos monetarios de la fuerza de trabajo ocupada, en general, y de la joven, de 18 a 29 ańos, en particular, residentes en el Gran Buenos Aires para el periodo de la postconvertibilidad (2004-2014). La literatura expone que, si bien los jóvenes cuentan con niveles más elevados de educación formal y un mejor manejo de

\footnotetext{
El presente artículo se desarrolla y desprende de otros trabajos realizados previamente en el contexto del proyecto UBACyT "Heterogeneidad estructural, desigualdad distributiva y nuevas marginalidades sociales (1974-2014)", dirigido por el Dr. Agustín Salvia, con sede en el Programa Cambio Estructural y Desigualdad Social del Instituto de Investigaciones Gino Germani de la Universidad de Buenos Aires. "This article was elaborated in the context of INCASI Network, a European project that has received funding from the European Union's Horizon 2020 research and innovation programme under the Marie Skłodowska-Curie GA No 691004 and coordinated by Dr. Pedro López-Roldán". "This article reflects only the author's view and the Agency is not responsible for any use that may be made of the information it contains".

"Licenciada en Sociología de la Universidad de Buenos Aires, Magister en Diseño y Gestión de Programas Sociales por Flacso, y becaria doctoral UBACyT en Ciencias Sociales por la Universidad de Buenos Aires del programa Cambio Estructural y Desigualdad con sede en el Instituto de Investigaciones Gino Germani (IIGG-UBA). Correo e.: beer.rubio@gmail.com

${ }^{* * *}$ Licenciada en Sociología de la Universidad de Buenos Aires y becaria doctoral Conicet del programa Cambio Estructural y Desigualdad con sede en el Instituto de Investigaciones Gino Germani (IIGG-UBA). Correo e.: mnoelfachal@gmail.com.

Fecha de recepción: 2310 17; Fecha de aceptación: 030518.
}

(cc) BY-NC-ND Páginas 59-98. 
las nuevas tecnologías - y con ello una mejor adaptabilidad a contextos volátiles-, continúan teniendo mayores dificultades en materia laboral. El principal objetivo del presente estudio es analizar la evolución de los ingresos monetarios de la fuerza de trabajo joven evaluando el impacto que el sector de inserción y los niveles educativos alcanzados tienen en las remuneraciones y su forma de distribución. El análisis se encuadra en una metodología cuantitativa a través de la utilización de los microdatos de la Encuesta Permanente de Hogares del Instituto Nacional de Estadísticas y Censos, Indec, aplicando pruebas de regresión lineal múltiple con el fin de otorgar mayor robustez a los resultados alcanzados.

Palabras clave: juventud, mercado de trabajo, educación, desigualdad remunerativa.

Abstract: This paper deals with the relationship between formal education, job placement and monetary income of the employed workforce in general, and of the young workforce, aged 18 to 29, in particular, living in the Gran Buenos Aires during the post-convertibility period (20042014). The literature shows that, although young people have higher levels of formal education, better management of new technologies —and with it a better adaptability to volatile contexts-, they continue to have greater difficulties in labor matters. The main objective of the present study is to analyze the evolution of the monetary income of the young workforce by evaluating the impact that the sector of insertion and the educational levels reached have on the remunerations and their form of distribution. The analysis is framed in a quantitative methodology through microdata from the Permanent Household Survey of Indec, applying multiple linear regression tests in order to give greater robustness to the results achieved.

Keywords: youth, labour market, education, remunerative inequality. 


\section{Introducción}

La modificación y diversificación de la estructura productiva de nuestras economías requiere de la creación y crecimiento de sectores de alta productividad con grandes innovaciones tecnológicas que puedan ser acompañadas de una intensa incorporación de conocimiento (PNUD, 2011; Cepal, 2014, 2015; OIT, 2015). Con el objetivo de alcanzar la igualdad en las economías de la región, el debate político y académico se ha dedicado a pensar la educación y el empleo como los dos ámbitos claves para el crecimiento con inclusión social, específicamente en torno al potencial que representa para el desarrollo de las capacidades de las nuevas generaciones.

Es durante la etapa de la juventud el momento más oportuno para vincular educación y trabajo en clave de inclusión social. Aunque con el tiempo los jóvenes hayan ido alcanzado mayores niveles educativos respecto a las anteriores generaciones, continúan sufriendo dificultades en materia laboral. Sus inserciones laborales son de peor calidad, sus salarios más bajos y cuentan con un menor grado de afiliación a los sistemas de seguridad social, quedando por fuera de los procesos de integración social y autonomía.

En Argentina son numerosos los estudios empíricos que analizan el deterioro desde la dictadura militar hasta hoy en las condiciones de vida de los jóvenes y que destacan cuan vulnerables son a los cambios estructurales y la falta de inclusión social, siendo más proclives a caer en la desocupación, la precariedad laboral y el déficit escolar ante un mercado que cada vez demanda más exigencias. Si bien la crisis socioeconómica del año 2001 no fue especialmente perjudicial para este grupo, el periodo de recuperación posterior no resultó de la misma manera para los jóvenes respecto a los adultos. De esta forma, el problema de los jóvenes no parece tener soluciones en los cambios de ritmo económico, encontrándose notablemente condicionadas por el proceso de segmentación de la estructura de oportunidades sociales (Salvia y Tuñón, 2007; Bonfiglio, Salvia, Tinoboras y Van Raap, 2008; Maurizio, 2011).

En este sentido, interesa aquí analizar los rasgos de una economía capitalista periférica y dependiente como la argentina, especialmente la 
"heterogeneidad estructural". Este concepto remite a la coexistencia de un sector económico con una productividad media del trabajo relativamente próxima a la que permiten las técnicas disponibles a nivel del mercado mundial - y en el que se concentran las inversiones y el progreso técnico con un conjunto de actividades rezagadas-. Los patrones de empleo y distribución que se originan a partir de esta estructura heterogénea tienden a ser profundamente regresivos. ${ }^{1 .}$ Un aspecto fundamental en términos de su impacto sobre el mercado de trabajo es la incapacidad del sector dinámico de absorber a toda la fuerza de trabajo disponible en la sociedad, como resultado de lo cual una parte de ella se debe autoemplear en actividades de baja productividad (Prebisch, 1949; Pinto, 1976; Ocampo, 2001; Rodríguez, 2001). Esto último sin dejar de tener en cuenta que las características de los ciclos macroeconómicos que atraviesa una economía también cumplen un papel importante en el comportamiento de la demanda agregada de empleo, influyendo sobre las tasas generales de absorción de mano de obra. ${ }^{2}$

En este contexto, cabe preguntarse por el lugar que ocupan los jóvenes en el marco de sociedades heterogéneas y segmentadas. El presente trabajo pretende aportar elementos empíricos que permitan retomar y responder ciertos interrogantes: ¿Cuáles son los principales rasgos asumidos por el vínculo entre educación e inserción sectorial de la fuerza de trabajo joven durante el periodo de la postconvertibilidad? ¿Cuál es el comportamiento de los ingresos de la fuerza de trabajo joven en función del nivel educativo y del sector de inserción en cada una de ellas? ¿Cuál es la elasticidad del ingreso, controlando los factores antes mencionados?

Con miras a dar respuesta a los interrogantes formulados se trabaja con un recorte etario de los microdatos de la Encuesta Permanente de Hogares del Instituto Nacional de Estadísticas y Censos, Indec, correspondientes al Gran Buenos Aires, GBA —conformado por la Ciudad Autónoma de Buenos Aires y la envolvente urbana que

\footnotetext{
${ }^{1}$ La tesis de la heterogeneidad estructural dio forma al programa inicial de la Comisión Económica para América Latina y el Caribe (Prebisch, 1949, 1970). Actualmente, Cepal ha retomado parcialmente el enfoque como marco interpretativo del persistente subdesarrollo latinoamericano (Cimoli 2005; Cepal, 2010).

${ }^{2}$ Véase Tabla A1 en Anexo.
} 
incorpora a los 24 municipios de la conurbación que la rodea- ${ }^{3}$, en su modalidad continua, reparando en un conjunto de años específicos — cuartos trimestres de 2004, 2007, 2012 y 2014- que permiten abordar la evolución de los fenómenos analizados. Se muestra además el comportamiento del total de la población ocupada, de 18 a 65 años para los mismos años ventana, en pos de detectar la especificidad del grupo joven en el conjunto de los trabajadores.

La exposición se organiza del siguiente modo. En la primera parte, se presenta el debate teórico que subyace al presente trabajo. La segunda sección analiza las tendencias generales de las principales variables analizadas: sector de inserción y nivel educativo. Una tercera parte, que constituye el aporte específico de este documento, se aboca a registrar la senda recorrida por los ingresos laborales horarios de los jóvenes según nivel educativo y sector de inserción, en el marco de las tendencias generales en el conjunto de la población ocupada. Por último, se presentan modelos de regresión lineal múltiple para explicar el comportamiento de la variación proporcional en los ingresos a lo largo del periodo, específicamente para la fuerza de trabajo joven. El texto concluye con algunas reflexiones finales.

\section{Debate teórico}

La emergencia de nuevas problemáticas sociales en las últimas décadas trae aparejada una mayor vulnerabilidad y desestandarización de las trayectorias de integración social para los jóvenes latinoamericanos. Por esta razón, la definición de juventud en términos etarios se ha ido extendiendo en edades cada vez más avanzadas, ya que representa la transición de la pubertad a la emancipación familiar plena. Particularmente en Argentina, la problemática de la exclusión juvenil ha cobrado marcada relevancia en la agenda pública debido a la persistencia de altas tasas de desocupación e inestabilidad laboral que

\footnotetext{
${ }^{3}$ Según datos de Indec, el Aglomerado Gran Buenos Aires (GBA) ocupa una superficie total de 2,590 kilómetros cuadrados y reúne 12.8 millones de habitantes, lo cual representa una concentración cercana a $32 \%$ de la población total del país; asimismo, produce alrededor de $40 \%$ del PBI nacional. Debido a esta destacada participación económico-demográfica, GBA se ha constituido en el centro productivo, comercial, financiero y político más importante del país (Indec, 1999).
} 
afectan a este grupo etario. En este sentido, existe consenso en que los jóvenes constituyen uno de los grupos más perjudicados por la crisis del mercado laboral argentino y en que, además, el deterioro que atraviesan sus inserciones socio ocupacionales son difícilmente reversibles a lo largo de sus trayectorias laborales (Salvia y Miranda, 2003; Jacinto, 2004; Cepal-OIJ, 2004; Miranda, Otero y Zelarayan, 2005; Pérez, 2008; Cepal, 2014, 2015).

Qué papel juegan los logros educativos en la estructuración de estas desigualdades es el interrogante más recurrente. Bajo diferentes enfoques, todos ellos situados en el marco de la Teoría del Capital Humano, las desventajas que exhibe la población joven a la hora de ingresar y permanecer ocupado en el mercado laboral se analizan a partir de una ausencia o carencia relativa de suficientes credenciales educativas -0 capacitación laboral — para lograr adecuarse a los requerimientos de la demanda de empleo (Schultz, 1961; Becker, 1962; Terrones y Calderón, 1993). Bajo el enfoque mencionado, el incremento del nivel educativo entre la población impactaría positivamente sobre el mercado laboral en dos dimensiones específicas: a) la difusión de mayores niveles educativos mejoraría la productividad laboral, la calidad y las remuneraciones de los puestos de trabajo; y b) el crecimiento general de la formación educativa impactaría de forma indirecta sobre la productividad global de la estructura productiva, generando mayor cantidad de ocupaciones con mayores exigencias de calificación, productividad y nivel de ingreso (Becker, 1962; Hatch y Dyer, 2004; Giménez, 2005; Herrera, 2010; Briceño, 2011). En este contexto, dadas las demandas que realiza la estructura productiva, una parte no menor de la población joven no podría insertarse u obtener remuneraciones acordes con empleos de calidad debido a niveles de formación insuficientes; entonces, desde esta perspectiva, un incremento sensible de la formación educativa entre los jóvenes impactaría positivamente en la calidad de sus empleos y en el nivel de ingreso.

El enfoque de los mercados segmentados, por su parte, argumenta que en el mercado de trabajo convive un segmento primario de empleo que se define por la presencia de ocupaciones estables, bien remuneradas y cubiertas por las reglamentaciones laborales vigentes, y un 
segmento secundario que es caracterizado por la inestabilidad, la alta rotación de mano de obra, los bajos salarios y la poca o nula posibilidad de representación gremial. Los puestos de trabajo que se ubican en cada segmento ostentan calidades diferenciadas y asimétricas que se traducen en diferentes formas de reclutamiento de la fuerza de trabajo (Reich, Gordon y Edwards, 1973; Piore, 1983). A la vez, en el caso de las economías latinoamericanas, la segmentación laboral se ve reforzada por la concentración de las capacidades de acumulación de capital y uso de tecnología en sectores de actividad insuficientes para absorber al conjunto de la oferta de trabajo (Mezzera, 1992; Vera, 2013). Este fenómeno no sólo da lugar a la conformación de estratos sectoriales con heterogéneas capacidades técnicas y de capitalización, sino que también obtura el alcance de las instituciones de regulación laboral y da lugar a la conformación de un sector de baja o nula productividad donde prevalecen los empleos inestables antes mencionados ${ }^{4}$ (Tokman, 2001; Salvia y Vera 2013). Desde esta perspectiva, el papel de la educación acompañaría el proceso de inserción de los jóvenes, posibilitando su integración o no a diferentes grupos de ocupaciones, pero de forma no unívoca, ya que estaría mediatizada por factores institucionales y técnico-productivos característicos del proceso de acumulación que estructuran al mercado de trabajo. En trabajos previos (Salvia y Vera 2015; Salvia, Robles y Fachal 2017, en prensa), se llevaron adelante análisis econométricos acerca del impacto que introduce la heterogeneidad sectorial de la demanda de empleo sobre las bonificaciones del retorno educativo, tanto en materia de remuneraciones como de oportunidades de empleo. Sin embargo, los mismos no enfatizaron en la particular situación laboral que enfrentan los jóvenes. Asimismo se ha avanzado sobre el estudio de la problemática de la inserción laboral de los jóvenes a partir del análisis del comportamiento de las formas sectoriales de empleo, de la segmentación del mercado de trabajo y de la determinación de los ingresos laborales durante las últimas dos décadas pero sin profundizar en el rol de la educación en estos procesos (Rubio

\footnotetext{
${ }^{4}$ Véase como estudio antecedente Rubio y Salvia (2018), en donde se desarrolla en profundidad las diversas modalidades de contratación en el Sector Público argentino y los efectos que tiene sobre la definición de regulación que se toma en este trabajo, particularmente para los jóvenes.
} 
y Salvia, 2018), e incluso sin realizar una comparativa con el total de la población ocupada del GBA (Rubio, Fachal y Robles, 2017).

Es ineludible que, al cambiar las condiciones económicas, sociales y culturales, el panorama educativo y laboral se transforme radicalmente. En la actualidad los jóvenes cuentan con más años de escolaridad en relación con las generaciones anteriores, pero esto no encontraría su correlato en una mejor calidad educativa. La creciente debilidad de la institución escolar, que supo ser definida como un motor de ascenso social, se ha constituido en un mecanismo de reproducción de la pobreza y la desigualdad; en otras palabras, como un espacio de socialización y distribución de capitales, saberes y calificaciones que ha perdido su función tradicional de estructuración de proyectos y expectativas para los jóvenes (Salvia, 2008; Tunón, 2011; Pérez, Deleo y Fernández, 2013).

De esta forma, la inclusión social a través de la educación y del trabajo se ve cada vez más afectada por los procesos de segmentación que atraviesan estos ámbitos, provocando oportunidades diferenciales para los jóvenes que quiebran los tradicionales activos relevantes para la movilidad social. Siguiendo a Katzman (2000), cuando los recursos y la estructura de oportunidades dejan de coincidir, se producen condiciones de vulnerabilidad social. Aunque es importante destacar que muchas veces los cambios en los requerimientos de acceso a la estructura de oportunidades son más rápidos que las posibilidades de los grupos de producir recursos necesarios para aprovechar dicha estructura de oportunidades.

Ahora bien, mientras que en la década de los 90 Argentina experimentó una serie de reformas estructurales aperturistas y promercado, que dificultaron las posibilidades de inclusión de los jóvenes, en el 2000 se inicia una etapa de signo heterodoxo con políticas orientadas al mercado interno en un contexto internacional favorable que permitió, [...] 
en general, recuperar los principales indicadores sociolaborales. ${ }^{5}$ De ahí que el presente desarrollo se propone analizar cuan favorable fueron a la situación laboral de los jóvenes las mencionadas políticas de signo contrario a las del periodo anterior.

\section{Principales tendencias de las características de inserción ocupacional de los jóvenes del área metropolitana}

En un primer momento se busca caracterizar a la población de ocupados del aglomerado del Gran Buenos Aires, distinguiendo asimismo a los jóvenes de 18 a 29 años. De esta forma se hace hincapié en la situación laboral de este grupo sin perder de vista al conjunto de los trabajadores.

Las tasas de actividad en el aglomerado del Gran Buenos Aires en los años bajo análisis (ver Tabla 1) rondan entre 74\% y 77\% para el total de ocupados de 18 a 65 años, y entre $66 \%$ y $75 \%$ cuando profundizamos el análisis al interior del grupo de jóvenes de 18 a 29 años. En este sentido, podemos observar las mayores tasas de desocupación que tienen los jóvenes para todos los años, que superan en un promedio de 5 puntos porcentuales a las tendencias observadas en el total de la población. Especialmente en el año inmediato a la salida de la crisis, en

\footnotetext{
${ }^{5}$ A partir del año 2003 se inicia en nuestro país el periodo de salida de la crisis (2001) y recuperación económica. Si bien no hay dudas acerca de las transformaciones en el tipo de intervención social que fueron cobrando relevancia respecto al modelo previo, no todos los hogares pudieron beneficiarse de igual forma a lo largo de todos estos años de cambio en las condiciones macroeconómicas. Cuando se observa lo sucedido con la concentración de los ingresos de los hogares, se evidencia que, si bien disminuyó sensiblemente al iniciarse la fase expansiva, luego su comportamiento fue más estable. Esto se relaciona con que hacia el año 2007 comienzan a evidenciarse algunos problemas que hicieron que el esquema macroeconómico adoptado hasta el momento comenzara a perder coherencia y a cambiar de rumbo progresivamente (Damill y Frenkel, 2015). El problema más notorio en este sentido fue el acelerado proceso inflacionario que indicó el comienzo de una nueva etapa cuyas dificultades se articularon más adelante con los impactos derivados de la crisis mundial iniciada a finales de 2008. Los limitantes propios del patrón de crecimiento adoptado en la postconvertibilidad se combinaron con los impactos negativos de la crisis internacional a nivel local, agudizando la contracción del nivel de actividad y la pérdida de competitividad de los sectores productivos poniéndose de manifiesto un deterioro general de la situación económica y laboral (Cenda, 2010; Wainer y Schorr, 2014). De esta forma, la recuperación del poder adquisitivo de los ingresos de los hogares comienza a desacelerarse, manteniéndose constante hasta 2010, teniendo su correlato en materia de reducción de la desigualdad (Beccaria y Maurizio, 2012). En este sentido, hacia el último tramo de este periodo -2010-2014 — las antiguas tensiones de la economía argentina vuelven a emerger.
} 
2001, y posteriormente la caída pero a porcentajes siempre por encima del total de los trabajadores.

Resulta importante señalar que, aun reconociendo que ambos grupos no son comparables entre sí —ya que los jóvenes constituyen un recorte del universo de estudio más general—- permite contextualizar la situación particular que atraviesa a los jóvenes frente a las tendencias más generales evidenciadas para el total de los trabajadores sin distinciones etarias. En este marco, los jóvenes — tal como también suele suceder en el caso de las mujeres - son los grupos que principalmente se suman a la oferta laboral como estrategia para no ver disminuidos los ingresos familiares, sobre todo en momentos de crisis. Esto es lo que la literatura especializada denomina "efecto del trabajador adicional" (Cepal, 2010, 2014; Maurizio, 2011; Weller, 2003, 2006; entre otros). En este sentido podemos ver que hacia el año 2004, inmediatamente después de la crisis del 2001-2002, este grupo registra altas tasas de actividad y desocupación, respecto a lo que sucede en los demás años.

Tabla 1. Tasas de actividad, de desocupación y de subempleo horario según grupos de edad. GBA: 2004, 2007, 2012 y 2014.

\begin{tabular}{|c|c|c|c|c|}
\hline \multicolumn{5}{|c|}{ Tasa de actividad $(\text { PEA })^{\mathrm{i}}$} \\
\hline & 2004 & 2007 & 2012 & 2014 \\
\hline Activos de 18 a 65 ańos & $77,4 \%$ & $76,2 \%$ & $75,8 \%$ & $74,3 \%$ \\
\hline $\begin{array}{c}\text { Activos Jóvenes } 18 \text { a } 29 \\
\text { años }\end{array}$ & $75,1 \%$ & $70,7 \%$ & $70,8 \%$ & $66,4 \%$ \\
\hline \multicolumn{5}{|c|}{ Tasa de desocupación ${ }^{\mathrm{ii}}$} \\
\hline & 2004 & 2007 & 2012 & 2014 \\
\hline Activos de 18 a 65 años & $12,9 \%$ & $10,7 \%$ & $9,6 \%$ & $7,6 \%$ \\
\hline $\begin{array}{c}\text { Activos Jóvenes } 18 \text { a } 29 \\
\text { ańos }\end{array}$ & $20,2 \%$ & $11,8 \%$ & $12,8 \%$ & $12,8 \%$ \\
\hline \multicolumn{5}{|c|}{ Tasa de subempleo horario ${ }^{\mathrm{iii}}$} \\
\hline & 2004 & 2007 & 2012 & 2014 \\
\hline Activos de 18 a 65 ańos & $15,9 \%$ & $13,1 \%$ & $12,4 \%$ & $10,1 \%$ \\
\hline $\begin{array}{c}\text { Activos Jóvenes } 18 \text { a } 29 \\
\text { años }\end{array}$ & $8,0 \%$ & $5,1 \%$ & $5,9 \%$ & $6,2 \%$ \\
\hline
\end{tabular}




\begin{tabular}{|c|c|c|c|c|}
\hline \multicolumn{5}{|c|}{ Tasa de precariedad $^{\text {iv }}$} \\
\hline & 2004 & $\mathbf{2 0 0 7}$ & $\mathbf{2 0 1 2}$ & $\mathbf{2 0 1 4}$ \\
\hline Activos de 18 a 65 años & $54,7 \%$ & $50,7 \%$ & $48,8 \%$ & $46,3 \%$ \\
\hline $\begin{array}{c}\text { Activos Jóvenes 18 a 29 } \\
\text { años }\end{array}$ & $63,8 \%$ & $53,0 \%$ & $52,4 \%$ & $54,7 \%$ \\
\hline
\end{tabular}

i Población económicamente activa, PEA, es decir, ocupados y desocupados, residentes en GBA sobre el total de la población residente en GBA.

ii Desocupados residentes en GBA sobre PEA residentes en GBA.

iii Subempleados demandantes residentes en GBA sobre PEA residentes en GBA.

iv Dicha tasa se ha conformado a partir de la construcción de la variable de segmento que elaboró PCEyDS. Retomando el enfoque institucionalista norteamericano, la demanda laboral queda estratificada en tres grandes segmentos de empleo: segmento primario o empleos regulados, segmento secundario o empleos extralegales y segmento terciario o empleos de indigencia, como empleos no regulados (ver Tabla A2 en Anexo). De acuerdo con esta corriente no existe un único mercado de trabajo sino diferentes segmentos bajo marcos institucionales disímiles, representando desiguales modalidades de inserción, relaciones laborales y calidad de los puestos de trabajo (Piore, 1975). En la tabla se presenta como tasa de precariedad, la participación del segmento no regulado sobre el total de ocupados.

Fuente: Elaboración propia con base en la información procesada por el Programa Cambio Estructural y Desigualdad Social, IIGG-FCS-UBA, a partir de EPH, Indec (GBA, cuartos trimestres de 2004, 2007, 2012 y 2014).

En otro sentido, los jóvenes presentan menores tasas de subempleo horario para todos los años. Entendemos que esto responde al momento del ciclo de vida, ya que la juventud es una etapa de diferentes tipos de transiciones, ya sea del sistema educativo al laboral, como en conformación de uniones y/o familias e incluso independencia residencial. Estas cuestiones son importantes para pensar la disponibilidad de horas destinadas al trabajo en este grupo. No sólo los jóvenes pueden estar demandando menos cantidad de horas de trabajo debido, por ejemplo, a estar todavía insertos en el sistema educativo, sino que en su mayoría probablemente aún sean trabajadores secundarios — hijos u otros familiares - en los hogares que conforman. Este tipo de arreglos son los que entendemos explican las tasas invertidas de subempleo respecto a las de desocupación y actividad.

Por último, los jóvenes se encuentran sobrerrepresentados entre los trabajadores con empleos precarios en el periodo bajo análisis, 
superando en todos los años 52\% de los casos. Anteriores estudios ya han confirmado que los jóvenes continúan accediendo a empleos de menor calidad respecto a los adultos y tienen mayores dificultades para mantenerlos (Busso y Pérez 2010; Pérez, Deleo y Fernández Massi 2013; Fernández Massi, 2014; Rubio y Salvia 2018).

\section{Composición de la fuerza de trabajo ocupada total y joven según nivel educativo e inserción ocupacional}

Un primer análisis obliga a examinar los cambios ocurridos en el perfil educativo de la población ocupada en el área metropolitana del Gran Buenos Aires, a nivel general y para cada sector económico-ocupacional, a lo largo de la fase de políticas heterodoxas: 2004-2014. La Figura 1 brinda información relevante al respecto para los años ventana de estudio, registrando los cambios ocurridos en la distribución de la fuerza de trabajo por nivel educativo, a nivel general y por sector de inserción ocupacional. En ésta se presentan los máximos niveles de educación alcanzados por los ocupados clasificados en cuatro categorías: 1) Hasta Secundario Incompleto (HSI): ocupados sin instrucción, con primaria incompleta o completa y secundaria incompleta; 2) Secundario Completo (SC): ocupados con secundaria completa; 3) Terciario o Universitario Incompleto (TUI): ocupados con estudios terciarios o universitarios incompletos; y 4) Terciario o Universitario Completo (TUC): ocupados con estudios terciarios o universitarios completos. Por su parte, la Figura 2 describe esto último, pero para la población ocupada joven —entre 18 y 29 años.

En primer lugar, podemos observar el aumento del nivel educativo promedio de la población, expresándose esto en la caída de los ocupados con Hasta Secundario Incompleto en todos los sectores de inserción, siendo dicha caída más marcada en el Sector Público, y mucho menor en el Sector Micro Informal —en donde sólo disminuyó 3.7 puntos porcentuales entre puntas del periodo- De esta forma, el Sector Micro Informal se constituye en el principal sector refugio de los segmentos de baja calificación.

En paralelo a la tendencia registrada, considerando en conjunto a los niveles educativos más altos, se observa un aumento de la participación 
de estos trabajadores en los sectores más dinámicos. En segundo lugar, se confirma una participación significativa de la población con mayor nivel educativo tanto en el Sector Privado Formal como en el Sector Público - siendo en éste en donde se concentra el mayor peso de las titulaciones-. Por oposición, en el Sector Micro Informal la participación de trabajadores con niveles educativos altos no ha evidenciado grandes cambios a lo largo de esta fase —oscila alrededor de $10 \%$ en el caso de los trabajadores con terciario o universitario incompleto, y de $8 \%$ en el de los trabajadores que completaron dicho nivel educativo.

Figura 1. Composición de la fuerza de trabajo ocupada - 18 a 65 años - por nivel educativo según sector de inserción. GBA: 2004, 2007, 2012 y 2014.

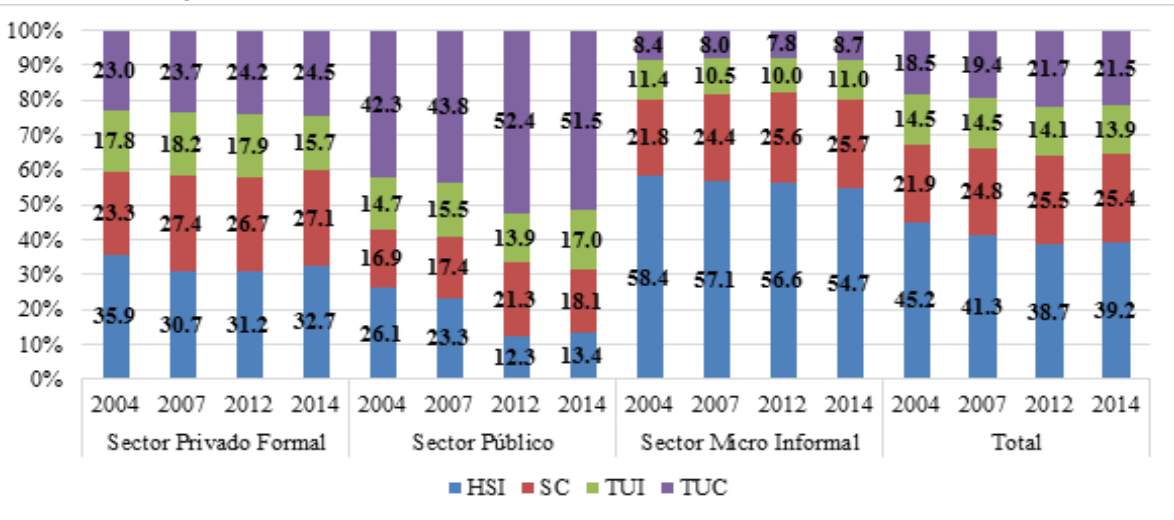

*Sector Público: Excluye empleados públicos ocupados en programas públicos de empleo.

Fuente: Elaboración propia con base en la información procesada por el Programa Cambio Estructural y Desigualdad Social, IIGG-FCS-UBA, a partir de EPH, Indec (GBA, cuartos trimestres de 2004, 2007, 2012 y 2014)

En tercer lugar, se constatan las diferencias estructurales presentes en la composición educativa de la fuerza de trabajo, según sector de inserción, entre el total de los ocupados y, específicamente, en la fuerza de trabajo joven. Mientras que la composición hacia el interior del Sector Privado Formal y Público da cuenta —en términos generalesde un comportamiento similar a aquel identificado a nivel agregado, en el Sector Micro Informal la participación de jóvenes con terciario o universitario incompleto es significativamente mayor. Mientras que en 
el total de los ocupados la participación de este nivel educativo oscila alrededor de $10 \%$ a lo largo del periodo, y entre los jóvenes en torno a $19 \%$. Esto último responde a factores generacionales que impactan en el tipo de inserción ocupacional — tales como la asistencia y no finalización del nivel educativo en curso- y que reflejan las especificidades de la fuerza de trabajo joven.

Figura 2. Composición de la fuerza de trabajo ocupada joven -18 a 29 años- por nivel educativo según sector de inserción. GBA: 2004, 2007, 2012 y 2014.

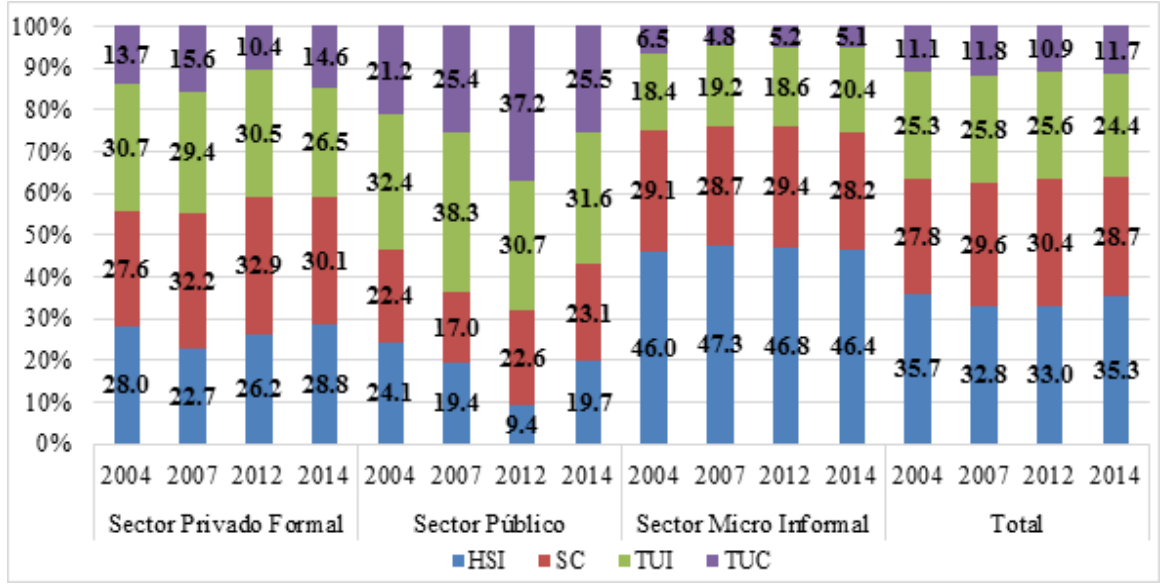

*Sector Público: Excluye empleados públicos ocupados en programas públicos de empleo.

Fuente: Elaboración propia con base en la información procesada por el Programa Cambio Estructural y Desigualdad Social, IIGG-FCS-UBA, a partir de EPH, Indec (GBA, cuartos trimestres de 2004, 2007, 2012 y 2014)

En este punto, retomamos las reflexiones anteriores en torno a este grupo, pero acentuando los vínculos entre la conformación de sus trayectorias educativas y el sector económico ocupacional en el que se encuentran insertos. Siendo que el grupo está compuesto por trabajadores de 18 a 29 años, es probable que se encuentren aún asistiendo a establecimientos educativos. En este sentido, los jóvenes están en riesgo competitivo con aquellos que han terminado sus estudios — jóvenes y/o adultos - y en una posición que los hace proclives a, por un lado, ser reclutados por el sector menos dinámico de la estructura productiva y, por otro, acceder a dichos puestos en pos 
de continuar formándose mientras adquieren ciertas competencias propias del mundo laboral. Ahora bien, a esto se agrega que siendo jóvenes y teniendo niveles educativos bajos también el Sector Micro Informal opera en el mismo sentido que lo hace a nivel agregado, esto es, como refugio de los trabajadores con pocas titulaciones.

\section{Comportamiento en la evolución de las brechas de ingreso de acuerdo con el nivel educativo y el sector de inserción ocupacional}

Según los enfoques que centran su atención en los atributos de la fuerza de trabajo - específicamente en su nivel de educación-, cabría esperar variaciones casi automáticas en las remuneraciones y en las brechas de ingresos laborales. Estos planteos se encuentran tanto en producciones locales como internacionales que, al apoyarse en postulados más o menos restringidos de la teoría del capital humano, enfatizan la importancia prioritaria de esta relación para explicar las desigualdades en la distribución de los ingresos laborales (Carlson, 2002; Giménez, 2005; Paz, 2007; Herrera, 2010). Sin embargo, la evidencia empírica no parece coincidir con esta teoría. Las diferentes tendencias observadas en el apartado anterior en las categorías de educación por sector económico ocupacional de inserción confirman las desigualdades estructurales que, además de otros factores, condicionan la dinámica de los premios laborales y sus desigualdades internas.

Con miras a avanzar en este sentido, se presentan a continuación las brechas de ingreso de los ocupados de acuerdo con su nivel educativo y sector de inserción laboral para los cuatro años tomados como ventana de observación. Estas brechas representan la distancia relativa que posee el ingreso horario medio en cada categoría respecto de la media de ingreso laboral horario para el total de los ocupados en cada año; por lo tanto, un valor mayor a 1 supone que dicha categoría se encuentra por encima de la media de ingreso del total de los trabajadores registrada para un año particular, mientras que un valor por debajo señala que dicho ingreso es inferior al promedio general. A través de los datos de 
la Tabla $2,{ }^{6}$ se hace evidente que las brechas de ingresos según sector de inserción se amplían a favor de los ocupados del Sector Público y del Privado Formal —en este caso, especialmente hasta la mitad del periodo, para luego disminuir, aunque situándose siempre por encima de la media de ingreso total_- y en desventaja para los ocupados del Sector Micro Informal. ${ }^{7}$ Estos datos reafirman la tesis de que una parte no menor de las desigualdades en la distribución del ingreso laboral tienen como protagonista a las unidades económicas según sus diferenciales en materia de productividad, estructura organizacional, el modo en que participan de los mercados de trabajo, regulaciones a las que están sometidas y vinculaciones con el resto del sistema económico (Salvia, 2012).

Respecto a la evolución de las brechas a lo largo del periodo, interesa destacar el particular crecimiento del Sector Público durante la postconvertibilidad, viéndose lo anterior reflejado en los ingresos. A lo largo de estos años, ha habido una sostenida creación de empleo público $\mathrm{y}$, con ello, la posibilidad de una carrera laboral propia de la misma dinámica estatal (Palomino, 2007; Neffa, 2012). Se puede ver que en los sectores restantes las brechas de ingreso tienden a disminuir y/o estancarse a lo largo del periodo. Esto último incluso sucede entre los niveles educativos más altos. Por su parte, el Sector Público es el único que aumenta progresivamente sus ingresos $-\mathrm{y}$ para todos los niveles educativos.

\footnotetext{
${ }^{6}$ En el anexo se encuentran las tablas A2 y A3 que muestran la evolución de las medias de ingresos laborales horarios reales según nivel educativo y sector de inserción respecto del total de la fuerza de trabajo ocupada y para la fuerza de trabajo joven (GBA: 2004, 2007, 2012 y 2014; en pesos del $4^{\circ}$ trimestre de 2014), a partir de las cuales se calcularon las brechas de ingreso.

${ }^{7}$ Dadas las limitaciones de la fuente de información utilizada no es posible obtener la importancia relativa en el Producto Bruto Interno, PBI, de cada sector de inserción. No obstante, se puede tomar como un ejercicio de aproximación la participación de los sectores en la masa de ingresos totales de la ocupación principal de los hogares en GBA. Promediando el periodo tomado para el análisis, del total de los ingresos generados por los hogares de GBA alrededor de $55 \%$ pertenece al Sector Privado Formal, alrededor de 30\% al Sector Micro Informal y aproximadamente $15 \%$ al Sector Público.
} 
Tabla 2. Evolución de las brechas entre las medias de ingresos laborales horarios reales según nivel educativo y sector de inserción, respecto del total de la fuerza de trabajo ocupada, 18 a 65 ańos. GBA: 2004, 2007, 2012 y 2014; en pesos del $4^{\circ}$ trimestre de 2014.

\begin{tabular}{|c|c|c|c|c|c|}
\hline & & 2004 & 2007 & 2012 & 2014 \\
\hline \multirow{5}{*}{$\begin{array}{l}\text { Sector } \\
\text { Privado } \\
\text { Formal }\end{array}$} & HSI & 0,71 & 0,74 & 0,74 & 0,77 \\
\hline & SC & 1,05 & 0,91 & 0,99 & 0,97 \\
\hline & TUI & 1,07 & 1,18 & 1,10 & 1,15 \\
\hline & TUC & 1,99 & 2,08 & 1,63 & 1,52 \\
\hline & Total & 1,15 & 1,18 & 1,09 & 1,07 \\
\hline \multirow{5}{*}{$\begin{array}{c}\text { Sector } \\
\text { Público* }\end{array}$} & HSI & 0,76 & 0,76 & 0,80 & 0,81 \\
\hline & SC & 1,02 & 1,02 & 1,18 & 1,10 \\
\hline & TUI & 1,09 & 1,25 & 1,20 & 1,48 \\
\hline & TUC & 1,73 & 1,69 & 1,63 & 1,84 \\
\hline & Total & 1,26 & 1,29 & 1,37 & 1,51 \\
\hline \multirow{5}{*}{$\begin{array}{c}\text { Sector Micro } \\
\text { Informal }\end{array}$} & HSI & 0,66 & 0,59 & 0,71 & 0,64 \\
\hline & SC & 0,94 & 0,76 & 0,76 & 0,80 \\
\hline & TUI & 0,96 & 1,05 & 0,83 & 1,00 \\
\hline & TUC & 1,22 & 1,24 & 1,11 & 1,14 \\
\hline & Total & 0,80 & 0,73 & 0,77 & 0,77 \\
\hline \multirow{5}{*}{ Total } & HSI & 0,68 & 0,65 & 0,73 & 0,70 \\
\hline & SC & 0,99 & 0,85 & 0,92 & 0,91 \\
\hline & TUI & 1,03 & 1,15 & 1,04 & 1,15 \\
\hline & TUC & 1,76 & 1,82 & 1,56 & 1,55 \\
\hline & Total & 1 & 1 & 1 & 1 \\
\hline
\end{tabular}

*Excluye empleados públicos ocupados en programas de empleo transitorio.

Fuente: Elaboración propia con base en la información procesada por el Programa Cambio Estructural y Desigualdad Social, IIGG-FCS-UBA, a partir de EPH, Indec (GBA, cuartos trimestres de 2004, 2007, 2012 y 2014)

Al prestar atención a la Tabla 3, en donde se presenta la evolución de las brechas de ingreso entre los jóvenes, se replican las tendencias observadas para el conjunto de los ocupados con algunas diferencias. En primer lugar, las brechas de ingresos correspondientes al Sector Público son mayores que las evidenciadas para el Sector Privado Formal 
pero menores que aquellas registradas a nivel agregado. En este sentido vemos que la tendencia progresiva del Sector Público observada en el total disminuye específicamente para este grupo etario. Esto se podría asociar a las diferentes modalidades de contratación que presenta el ámbito público en Argentina, en donde este grupo suele estar más expuesto a contratos de mayor inestabilidad y precarización debido a que recientemente se incorporan al mundo laboral y, en este caso, a la carrera en la administración pública (Rubio y Salvia, 2018). Asimismo, es común que en este sector, y sobre todo bajo dichas modalidades de contratación, los jóvenes sean reclutados para puestos de menor cantidad de horas - que nuevamente llevaría a la reflexión en torno a las ventajas que esto último puede traerle a un joven que aún se encuentra cursando sus estudios-y con ello menores ingresos.

Por otro lado, si bien las brechas de ingreso confirman también las desventajas evidenciadas entre los ocupados jóvenes del Sector Micro Informal, son levemente menores con respecto a lo identificado a nivel general. Esto también abonaría a las anteriores consideraciones respecto a los arreglos de inserción por parte de la oferta de trabajo, ya que al considerar la media del sector parecería que, en el mismo, los niveles de educación más altos entre los jóvenes son más premiados que en el conjunto de los trabajadores —en particular, hasta el año 2012-. Mientras que, en general, en el Sector Público y en el Privado Formal las titulaciones medias también son premiadas -situándose levemente por encima de la media general-, esto no sucede en el Sector Micro Informal.

En este punto, resulta interesante observar qué sucede al centrar la atención en la evolución de las medias de ingresos laborales horarios entre varones y mujeres. La Tabla 4 muestra $^{8}$ que, a pesar de que en ciertos ańos o niveles educativos la brecha de ingreso entre varones $y$ mujeres se amplía en beneficio de los primeros o se reduce en beneficio de las segundas, en términos generales se evidencia la ausencia de diferencias significativas de género en las remuneraciones horarias. Ahora bien, se debe tener en cuenta que las participaciones en el

\footnotetext{
${ }^{8}$ En el anexo se encuentra la Tabla A5 que muestra la evolución de las medias de ingresos laborales horarios reales para varones y mujeres según nivel educativo y sector de inserción, respecto del total de la fuerza de trabajo joven (GBA: 2004, 2007, 2012 y 2014; en pesos del $4^{\circ}$ trimestre de 2014), a partir de la cual se calcularon las razones entre las medias de ingreso.
} 
mercado de trabajo según se trate de varones y mujeres es diferente y variable en el tiempo (Salvia y Tunón, 2007).

A continuación, se analizarán las brechas de ingresos a partir de modelos de regresión lineal múltiple en donde se evaluará nuevamente el papel del género en las remuneraciones horarias promedio al controlar por otros factores.

Tabla 3. Evolución de las brechas entre las medias de ingresos laborales horarios reales según nivel educativo y sector de inserción, respecto del total de la fuerza de trabajo ocupada joven, 18 a 29 años. GBA: 2004, 2007, 2012 y 2014; en pesos del $4^{\circ}$ trimestre de 2014.

\begin{tabular}{|c|c|c|c|c|c|}
\hline & & 2004 & 2007 & 2012 & 2014 \\
\hline \multirow{5}{*}{$\begin{array}{l}\text { Sector } \\
\text { Privado } \\
\text { Formal }\end{array}$} & HSI & 0,78 & 0,79 & 0,72 & 0,79 \\
\hline & SC & 1,13 & 0,97 & 1,05 & 0,97 \\
\hline & TUI & 1,29 & 1,29 & 1,27 & 1,32 \\
\hline & TUC & 1,59 & 1,64 & 1,22 & 1,43 \\
\hline & Total & 1,15 & 1,13 & 1,05 & 1,08 \\
\hline \multirow{5}{*}{$\begin{array}{c}\text { Sector } \\
\text { Público* }\end{array}$} & HSI & 0,72 & 0,61 & 0,74 & 0,80 \\
\hline & SC & 1,09 & 0,76 & 1,20 & 1,21 \\
\hline & TUI & 1,31 & 1,39 & 1,30 & 1,39 \\
\hline & TUC & 1,35 & 1,45 & 1,52 & 1,43 \\
\hline & Total & 1,14 & 1,15 & 1,31 & 1,25 \\
\hline \multirow{5}{*}{$\begin{array}{l}\text { Sector Micro } \\
\text { Informal }\end{array}$} & HSI & 0,66 & 0,63 & 0,72 & 0,72 \\
\hline & SC & 0,75 & 0,71 & 0,85 & 0,97 \\
\hline & TUI & 1,11 & 1,24 & 1,06 & 0,91 \\
\hline & TUC & 1,15 & 1,15 & 1,29 & 0,85 \\
\hline & Total & 0,81 & 0,80 & 0,86 & 0,84 \\
\hline \multirow{5}{*}{ Total } & HSI & 0,71 & 0,69 & 0,72 & 0,75 \\
\hline & SC & 0,95 & 0,85 & 0,98 & 0,98 \\
\hline & TUI & 1,24 & 1,29 & 1,21 & 1,19 \\
\hline & TUC & 1,44 & 1,53 & 1,34 & 1,32 \\
\hline & Total & 1,00 & 1,00 & 1,00 & 1,00 \\
\hline
\end{tabular}

*Excluye empleados públicos ocupados en programas de empleo transitorio.

Fuente: Elaboración propia con base en la información procesada por el Programa Cambio Estructural y Desigualdad Social, IIGG-FCS-UBA, a partir de EPH, Indec (GBA, cuartos trimestres de 2004, 2007, 2012 y 2014) 
Tabla 4. Razón ${ }^{9}$ entre las medias de ingreso laborales horarios reales de varones y mujeres según nivel educativo y sector de inserción. GBA: 2004, 2007, 2012 y 2014; en pesos del $4^{\circ}$ trimestre de 2014.

\begin{tabular}{|c|c|c|c|c|c|}
\hline & & 2004 & 2007 & 2012 & 2014 \\
\hline \multirow{5}{*}{$\begin{array}{l}\text { Sector } \\
\text { Privado } \\
\text { Formal }\end{array}$} & HSI & 1,02 & 0,95 & 0,95 & 0,95 \\
\hline & SC & 0,62 & 0,94 & 0,90 & 0,77 \\
\hline & TUI & 0,87 & 0,81 & 0,98 & 0,90 \\
\hline & TUC & 0,89 & 1,03 & 1,00 & 1,07 \\
\hline & Total & 0,98 & 1,02 & 1,06 & 1,08 \\
\hline \multirow{5}{*}{$\begin{array}{c}\text { Sector } \\
\text { Público* }\end{array}$} & HSI & 0,77 & 0,68 & 1,12 & 1,10 \\
\hline & SC & 0,96 & 0,85 & 0,93 & 0,67 \\
\hline & TUI & 0,81 & 0,48 & 0,80 & 0,61 \\
\hline & TUC & 0,93 & 0,94 & 1,23 & 0,72 \\
\hline & Total & 0,86 & 0,80 & 1,09 & 0,91 \\
\hline \multirow{5}{*}{$\begin{array}{l}\text { Sector Micro } \\
\text { Informal }\end{array}$} & HSI & 0,82 & 0,98 & 1,19 & 1,50 \\
\hline & SC & 0,79 & 0,77 & 0,77 & 0,89 \\
\hline & TUI & 0,70 & 0,69 & 0,72 & 0,51 \\
\hline & TUC & 1,26 & 0,51 & 0,85 & 0,98 \\
\hline & Total & 0,93 & 0,85 & 0,98 & 1,00 \\
\hline \multirow{5}{*}{ Total } & HSI & 0,87 & 0,93 & 1,11 & 1,24 \\
\hline & SC & 0,68 & 0,85 & 0,83 & 0,82 \\
\hline & TUI & 0,80 & 0,73 & 0,88 & 0,71 \\
\hline & TUC & 0,95 & 0,95 & 1,06 & 1,04 \\
\hline & Total & 0,94 & 0,93 & 1,05 & 1,03 \\
\hline
\end{tabular}

*Excluye empleados públicos ocupados en programas de empleo transitorio.

Fuente: Elaboración propia con base en la información procesada por el Programa Cambio Estructural y Desigualdad Social, IIGG-FCS-UBA, a partir de EPH, Indec (GBA, cuartos trimestres de 2004, 2007, 2012 y 2014)

\footnotetext{
${ }^{9}$ Un valor menor a 1 significa que el varón tiene un ingreso superior al de la mujer, y un valor mayor a 1 significa que es la mujer quien tiene un ingreso más elevado con respecto al varón.
} 


\section{Elasticidades en el ingreso horario de los ocupados jóvenes}

A continuación, presentamos una serie de modelos de regresión lineal múltiple para explicar el comportamiento de la elasticidad del ingreso a lo largo del periodo, específicamente para la fuerza de trabajo joven. En este sentido, la tesis que subyace a la aplicación de estos modelos es que los factores estructurales ejercen una influencia creciente sobre las diferencias en los ingresos laborales horarios, aun cuando se controlan otros factores como la educación.

Para ello, incorporamos como variables independientes explicativas el subgrupo etario, 18-24 años y 25-29 años, el sexo, el nivel educativo alcanzado, la asistencia o no al establecimiento educativo, el sector económico ocupacional de inserción y los años ventana de estudio analizados. En términos formales, el modelo ajustado queda representado a través de la siguiente ecuación (1):.

$$
\operatorname{Ln} \mathbf{Y}=\alpha_{0}+\beta_{1} \cdot \mathbf{X}_{1}+\beta_{2} \cdot \mathbf{X}_{2}+\beta_{3} \cdot \mathbf{X}_{3}+\beta_{4} \cdot \mathbf{X}_{4}+\beta_{5} \cdot \mathbf{X}_{5}+\beta_{6} \cdot \mathbf{X}_{6}+\mu(1)
$$

En este sentido, Ln Y representa el logaritmo natural de los ingresos horarios de los trabajadores jóvenes. El factor $\mathrm{X}_{1}$ expresa la influencia del subgrupo etario — con los jóvenes de 18 a 24 años como categoría de referencia-; el componente $\mathrm{X}_{2}$ controla el efecto del sexo — siendo las mujeres quienes ocupan la categoría de comparación-; el factor $\mathrm{X}_{3}$ representa el efecto del nivel educativo - tomando el nivel educativo más bajo como categoría de referencia-; el componente $\mathrm{X}_{4}$ constituye el efecto de la asistencia o no al establecimiento educativo; el factor $\mathrm{X}_{5}$ expresa el efecto del sector de inserción - tomando al Sector Micro Informal como comparación-; y el componente $\mathrm{X}_{6}$ refiere a la ventana temporal —considerando al año 2004 como categoría de referencia, ya que es el año base de "despliegue" de la etapa heterodoxa-. El término $\alpha_{0}$ representa el valor de la constante, la cual expone el efecto indiferenciado de las categorías de comparación de las variables predictores, cuando se reporta ausencia en cada una de las variables 
"dummy" introducidas. ${ }^{10}$ Por último, el factor $\mu$ constituye los efectos sobre la variable endógena ignorados por el modelo.

Ahora bien, estas variables que integran el primer modelo se replican para un segundo modelo pero incorporando la regulación del empleo como factor de control. Se ha decidido dicha incorporación debido a la conocida posición desfavorecida que tienen los jóvenes en el mercado laboral, accediendo a empleos de menor calidad y con mayores dificultades para mantenerlos pese a los cambios macroeconómicos progresivos que pudo haber atravesado el país a lo largo del periodo en cuestión. A partir de analizar la relación entre educación y sector de inserción, y su reflejo en la evolución de las remuneraciones horarias, se busca adicionar el efecto de la calidad del empleo entendiendo que es un factor explicativo de gran incidencia para pensar este tipo de vinculaciones, sobre todo en la población joven. Así, este segundo modelo ajustado queda representado a través de la siguiente ecuación (2), en donde el factor $\mathrm{X}_{7}$ da cuenta del efecto del empleo regulado.

$$
\operatorname{Ln} \mathbf{Y}=\alpha_{\mathbf{0}}+\beta_{1} \cdot \mathbf{X}_{1}+\beta_{2} \cdot \mathbf{X}_{2}+\beta_{3} \cdot \mathbf{X}_{\mathbf{3}}+\beta_{4} \cdot \mathbf{X}_{4}+\beta_{5} \cdot \mathbf{X}_{5}+\beta_{6} \cdot \mathbf{X}_{6}+\beta_{7} \cdot \mathbf{X}_{7}+\mu
$$

Habiendo desarrollado las principales características de los modelos aplicados, la Tabla 5 presenta los Coeficientes B de regresión y los coeficientes de correlación parcial tipificados, estimados por el método de mínimos cuadrados sobre el logaritmo natural de los ingresos horarios reales de los trabajadores ocupados jóvenes en el Gran Buenos Aires. Según los resultados alcanzados, $\mathrm{R}^{2}$ da cuenta de una bondad de ajuste del modelo que oscila entre $21 \%$ y $25 \%$.

\footnotetext{
${ }^{10}$ Dado el carácter no métrico de las variables independientes consideradas en el modelo teórico se adoptó el criterio de transformar las categorías de cada variable nominal en variables "dummy", 0 para ausencia y 1 para presencia de la característica, excluyendo en cada caso una categoría de comparación — cuya incidencia estimada es representada de manera indiferenciada por la constante.
} 
Tabla 5. Evolución de la incidencia de las variables seleccionadas sobre el logaritmo natural de los ingresos horarios de los OCUPADOS jóvenes. GBA: 2004-2007-20122014.

\begin{tabular}{|c|c|c|c|c|c|c|}
\hline \multirow{2}{*}{ Variables del modelo } & \multicolumn{3}{|c|}{$\begin{array}{c}\text { Total de ocupados } \\
\text { jóvenes } \\
\text { Paso I }\end{array}$} & \multicolumn{3}{|c|}{$\begin{array}{c}\text { Total de ocupados } \\
\text { jóvenes } \\
\text { Paso II } \\
\end{array}$} \\
\hline & B & Sig. & $\begin{array}{c}\text { Beta } \\
\text { tipificado }\end{array}$ & B & Sig. & $\begin{array}{c}\text { Beta } \\
\text { tipificado }\end{array}$ \\
\hline \multicolumn{7}{|l|}{ Subgrupo etario } \\
\hline \multicolumn{7}{|l|}{ Jóvenes de 18 a 24 ańos* } \\
\hline Jóvenes de 25 a 29 años & 0,132 & 0,000 & 0,088 & 0,093 & 0,000 & 0,062 \\
\hline \multirow{2}{*}{\multicolumn{7}{|c|}{ Mujer* }} \\
\hline & & & & & & \\
\hline Varón & 0,088 & 0,000 & 0,057 & 0,072 & 0,000 & 0,047 \\
\hline \multicolumn{7}{|l|}{ Nivel educativo alcanzado } \\
\hline \multicolumn{7}{|l|}{ Hasta secundario incompleto* } \\
\hline Secundario completo & 0,224 & 0,000 & 0,135 & 0,171 & 0,000 & 0,103 \\
\hline Terciario, universitario incompleto & 0,585 & 0,000 & 0,252 & 0,524 & 0,000 & 0,226 \\
\hline Terciario, universitario completo & 0,364 & 0,000 & 0,206 & 0,302 & 0,000 & 0,171 \\
\hline \multicolumn{7}{|l|}{$\begin{array}{l}\text { Asistencia a establecimiento } \\
\text { educativo }\end{array}$} \\
\hline \multicolumn{7}{|l|}{ No asiste* } \\
\hline Asiste & 0,110 & 0,000 & 0,060 & 0,122 & 0,000 & 0,067 \\
\hline \multicolumn{7}{|l|}{ Sector de inserción } \\
\hline \multicolumn{7}{|l|}{ Sector micro informal* } \\
\hline Sector privado formal & 0,297 & 0,000 & 0,196 & 0,148 & 0,000 & 0,098 \\
\hline Sector público & 0,364 & 0,000 & 0,144 & 0,213 & 0,000 & 0,084 \\
\hline \multirow{2}{*}{\multicolumn{7}{|c|}{$2004^{*}$}} \\
\hline & & & & & & \\
\hline 2007 & 0,213 & 0,000 & 0,129 & 0,187 & 0,000 & 0,113 \\
\hline 2012 & 0,415 & 0,000 & 0,236 & 0,384 & 0,000 & 0,218 \\
\hline 2014 & 0,351 & 0,000 & 0,206 & 0,326 & 0,000 & 0,191 \\
\hline
\end{tabular}




\begin{tabular}{|c|c|c|c|c|}
\hline Segmento de inserción & & & & \\
\hline No regulado* & & & & \\
\hline Regulado & & 0,353 & 0,000 & 0,232 \\
\hline Constante & 2,481 & \multicolumn{3}{|c|}{2,496} \\
\hline R2 corregida & 0,212 & \multicolumn{3}{|c|}{0,251} \\
\hline${ }^{*}$ Categoría de referencia & & & & \\
\hline
\end{tabular}

Fuente: Elaboración propia con base en la información procesada por el Programa Cambio Estructural y Desigualdad Social, IIGG-FCS-UBA, a partir de EPH, Indec (GBA, cuartos trimestres de 2004, 2007, 2012 y 2014)

Durante la fase de políticas heterodoxas (2003-2014), tuvo lugar un aumento relevante en las elasticidades por remuneración laboral en los ocupados jóvenes hasta el año 2012, para luego disminuir levemente en el ańo 2014. Por su parte, el retorno laboral de los ocupados jóvenes entre 25 y 29 años da cuenta de una razón de variación en su ingreso positiva y mayor con respecto a los ocupados con edades entre 18 y 24 años — quienes se encuentran en una posición de desventaja en términos de las remuneraciones percibidas-. Sin embargo, esta elasticidad es mucho menor en el segundo modelo que controla, además, el efecto de la regulación. Algo similar sucede al contemplar el sector de inserción. Mientras que los premios laborales por sector de inserción tienen un peso significativo en el primer modelo, en el segundo la regulación del empleo resta valor explicativo tanto al Sector Privado Formal como al Sector Público - los cuales, no obstante, se posicionan mejor en términos de ingreso con respecto al Sector Micro Informal- En este punto, cabe señalar que es precisamente esto último lo que conduce a realizar — como podrá observarse más adelante- un tercer modelo en el que se incorporan interacciones entre el sector de inserción y el empleo regulado o no regulado para controlar este efecto confusión observado.

Por otro lado, esto mismo se replica al contemplar el nivel educativo, pero en general son los jóvenes que ya han finalizado sus estudios quienes manifiestan retornos laborales más altos. Esto último adquiere aún mayor relevancia al controlar por la asistencia o no al establecimiento educativo, variable que se incorpora al modelo ya 
que entendemos que es importante para pensar los diferenciales en el riesgo competitivo que enfrentan los trabajadores jóvenes a la hora de insertarse en el mercado de trabajo que, generalmente, se encuentran atravesando una etapa de formación y desarrollo de capacidades y competencias para el mundo laboral.

Tal como fuera señalado anteriormente, dado el efecto confusión detectado al incorporar en el modelo la regulación del empleo, se procede a realizar un tercer ejercicio que agrega interacciones entre el sector de inserción de la fuerza de trabajo y la regulación o no del empleo joven. Este tercer modelo queda representado a través de la siguiente ecuación (3), en donde el factor $\mathrm{X}_{\mathrm{n}}$ da cuenta del efecto del "sector de inserción combinado con la regulación del empleo":

$$
\operatorname{Ln} \mathbf{Y}=\alpha_{0}+\beta_{1} \cdot \mathbf{X}_{1}+\beta_{2} \cdot \mathbf{X}_{2}+\beta_{3} \cdot \mathbf{X}_{3}+\beta_{4} \cdot \mathbf{X}_{4}+\beta_{5} \cdot \mathbf{X}_{5}+\beta_{n} \cdot \mathbf{X}_{\mathbf{n}}+\mu
$$

Contrariamente a las tendencias señaladas por la teoría del capital humano y coincidentemente con la teoría de la segmentación del mercado de trabajo, no sólo es posible observar el gran peso explicativo que tiene el sector de inserción y la regulación del empleo en la determinación del ingreso, sino que incluso llega a ser mayor que el nivel educativo.

Así, mientras las tendencias registradas en los modelos anteriores se sostienen al contemplar tanto los subgrupos etarios como el nivel educativo, la regulación hacia el interior de cada sector de inserción premia mientras que la no regulación castiga. Ahora bien, aun en estos últimos casos —en los que la no regulación disminuye ingresos- la inserción en el Sector Privado Formal o Público da cuenta de una variación proporcional del ingreso positiva con respecto al Sector Micro Informal no regulado —evidenciándose nuevamente aquí la clara situación de desventaja en la que se encuentran quienes se insertan en dicho sector.

Se entiende, además, como uno de los datos más relevantes de los modelos presentados que los jóvenes insertos en el sector Privado Formal sin regulación perciben salarios menores respecto a los jóvenes insertos en el sector Micro Informal que sí están regulados. Esto resulta de gran interés luego del desarrollo que se ha ido presentando, ya que 
agrega la importancia que tiene para los jóvenes las cuestiones asociadas a la calidad del empleo. A partir de la definición que tomamos aquí del segmento regulado, esto se asocia a las menores tasas de subocupación que presentaban los jóvenes, así como la ya desarrollada vinculación con ser proclives a acceder a empleos en establecimientos pequeños, en puestos de pocas horas y menores salarios, en pos de continuar y sostener una trayectoria educativa y a la vez permitiéndoles incorporar saberes y competencias del mundo laboral.

Tabla 6. Evolución de la incidencia de las variables seleccionadas sobre el logaritmo natural de los ingresos horarios de los OCUPADOS jóvenes. GBA: 2004-2007-20122014.

\begin{tabular}{|c|c|c|c|}
\hline \multirow[t]{2}{*}{ Variables del modelo } & \multicolumn{3}{|c|}{$\begin{array}{c}\text { Total de ocupados jóvenes } \\
\text { Paso I }\end{array}$} \\
\hline & $\mathrm{B}$ & Sig. & Beta tipificado \\
\hline \multirow{2}{*}{\multicolumn{4}{|c|}{$\begin{array}{l}\text { Subgrupo etario } \\
\text { Jóvenes de } 18 \text { a } 24 \text { años* }\end{array}$}} \\
\hline & & & \\
\hline Jóvenes de 25 a 29 años & 0,093 & 0,000 & 0,062 \\
\hline \multirow{2}{*}{\multicolumn{4}{|c|}{ Sexo }} \\
\hline & & & \\
\hline Varón & 0,072 & 0,000 & 0,047 \\
\hline \multirow{2}{*}{\multicolumn{4}{|c|}{$\frac{\text { Nivel educativo alcanzado }}{\text { Hasta secundario incompleto* }}$}} \\
\hline & & & \\
\hline Secundario completo & 0,171 & 0,000 & 0,103 \\
\hline Terciario, universitario incompleto & 0,523 & 0,000 & 0,225 \\
\hline Terciario, universitario completo & 0,302 & 0,000 & 0,171 \\
\hline \multicolumn{4}{|l|}{\begin{tabular}{|l|} 
Asistencia a establecimiento educativo \\
\end{tabular}} \\
\hline \multicolumn{4}{|l|}{ No asiste* } \\
\hline Asiste & 0,122 & 0,000 & 0,066 \\
\hline \multicolumn{4}{|l|}{ Interacciones Sector*Segmento } \\
\hline \multicolumn{4}{|l|}{ Sector micro informal ${ }^{*}$ No regulado } \\
\hline Sector micro informal ${ }^{*}$ Regulado & 0,360 & 0,000 & 0,129 \\
\hline Sector Privado Formal ${ }^{*}$ No regulado & 0,146 & 0,000 & 0,072 \\
\hline Sector Privado Formal ${ }^{*}$ Regulado & 0,503 & 0,000 & 0,304 \\
\hline Sector Público*No regulado & 0,242 & 0,000 & 0,056 \\
\hline Sector Público*Regulado & 0,555 & 0,000 & 0,184 \\
\hline
\end{tabular}




\begin{tabular}{|c|c|c|c|}
\hline Años & & & \\
\hline $2004^{*}$ & & & \\
\hline 2007 & 0,186 & 0,000 & 0,112 \\
\hline 2012 & 0,384 & 0,000 & 0,218 \\
\hline 2014 & 0,326 & 0,000 & 0,191 \\
\hline Constante & & 2,495 & \\
\hline R2 corregida & & 0,251 & \\
\hline
\end{tabular}

Fuente: Elaboración propia con base en la información procesada por el Programa Cambio Estructural y Desigualdad Social, IIGG-FCS-UBA, a partir de EPH, Indec (GBA, cuartos trimestres de 2004, 2007, 2012 y 2014)

Por último, si bien el sexo se ha incorporado sólo como una variable de control, puede apreciarse que los varones perciben ingresos laborales horarios $7 \%$ más alto que las mujeres, invirtiéndose las tendencias observadas en la Tabla 4. El comportamiento de la estructura productiva y las oportunidades de empleo pueden explicar esta tendencia.

\section{Reflexiones finales}

A lo largo del presente estudio hemos podido detectar especificidades que la fuerza de trabajo joven presenta en la relación entre las diferentes variables analizadas. Asimismo, estas vinculaciones resultaron de gran importancia para pensar en las incipientes trayectorias laborales que va conformando este grupo etario y que tendrán un gran peso en términos de continuidad y estabilidad en el mundo laboral a futuro.

Asimismo, el análisis para este periodo dio cuenta del potencial de los cambios de las políticas macroeconómicas heterodoxas, como así también de sus limitaciones, sobre todo para los grupos más vulnerables. Pese a los avances que se pueden detectar sobre todo en un primer momento postcrisis, este estudio permitió evidenciar que hace falta profundizar en políticas activas para los segmentos más desfavorecidos como los jóvenes.

Además, se han aportado nuevas evidencias en torno a la vinculación educación y trabajo, de valor para pensar en la inclusión social de los mismos, haciendo foco en la importancia de los sectores económico ocupacionales pero también en la diferencial calidad de los puestos 
que los mismos ofrecen. En particular se ha podido corroborar que las variaciones en las remuneraciones horarias y en las brechas de ingresos laborales no se ajustan primordialmente a los atributos de la fuerza de trabajo — específicamente a sus niveles de educación alcanzados-, sino que la desigualdad en la distribución de los ingresos responde más que nada a factores propios de la demanda. Las características del sector económico ocupacional, y de la calidad de los puestos que ofrecen, resultan de mayor importancia en la tasa de variación del ingreso, dando pie en este caso a los jóvenes, en momento de transiciones claves, a generar estrategias - muchas veces concediendo situaciones precarias - para adecuarse de la mejor manera posible a las características del reclutamiento del mundo laboral.

En este sentido, pese a la importancia que se le ha dado a factores estructurales de la demanda de empleo, se han podido contemplar algunas particularidades que tiene la oferta de fuerza de trabajo joven en términos de arreglos que son bien diferentes en este grupo por su condición de juventud y el rol que ocupan en los hogares que conforman. En este sentido, creemos que queda pendiente abordar una serie de dimensiones que den cuenta de forma más acabada estas cuestiones, ya sea diferenciales por sexo fuertemente asociados con el trabajo reproductivo, las estrategias laborales a partir de la incidencia de las políticas sociales y de empleo, así como la desagregación de las categorías ocupacionales, y la contemplación del origen de clase social. Esto podría precisar cuestiones vinculadas a la calidad del empleo al interior de cada sector de inserción, sobre todo sin perder de vista la relación con la educación.

En este sentido también, puede ser un gran aporte a futuro desagregar este análisis subdividiendo el grupo de jóvenes; diferenciando a los jóvenes recién egresados de la educación media, iniciando su trayectoria laboral en la mayoría de los casos, de 18 a 24 años, de aquellos con una carrera laboral incipientemente más establecida, con trayectorias educativas más definidas.

Los ejercicios de regresión lineal múltiple han podido complejizar las hipótesis ensayadas iluminando las particularidades de este grupo etario en su vinculación con las demandas del mundo del trabajo, 
pero también con los propios ajustes de la oferta. En síntesis, se han presentado interrogantes y evidencias empíricas que responden a los mismos; $y$, asimismo, se han abierto nuevas preguntas, que requieren ampliar y complejizar la evidencia empírica para ser respondidas.

\section{Bibliografia citada}

Beccaria, L. y R. Maurizio, 2012, “Reversión y continuidades bajo dos regímenes macroeconómicos diferentes. Mercado de trabajo e ingresos en argentina 1990-2010”, Desarrollo Económico, núm. 52, pp. 205-228.

Becker, G. S., 1962, "Investment in Human Capital: A Theoretical Analysis", The Journal of Political Economy, núm. 70, pp. 9-49, disponible en https://www.jstor.org/stable/1829103?seq=4\#page_scan_ tab_contents

Bonfiglio, J., A. Salvia, C. Tinoboras y V. Van Raap, 2008, Educación y trabajo. Un estudio sobre las oportunidades de inclusión de los jóvenes tras cuatro años de recuperación económica. Jóvenes promesas. Trabajo, educación y exclusión social de jóvenes pobres en la Argentina, Miño y Dávila, Buenos Aires, disponible en http://www.uca. edu.ar/uca/common/grupo68/files/EDUCACI-N_Y_TRABAJO._Salvia-_Van_Raap-Tinobras-_Bonfiglio1.pdf

Briceño, A., 2011, "La educación y su efecto en la formación de capital humano y en el desarrollo económico de los países", Apuntes Del CENES, vol. 30, núm. 51, pp. 45-59, disponible en https://dialnet.unirioja.es/servlet/articulo?codigo $=3724527$

Busso, M. y P. Pérez (coordinadores), 2010, La corrosión del trabajo. Estudios sobre informalidad y precariedad laboral, Miño y Dávila,CEILPIETTE, Trabajo y Sociedad, Buenos Aires, p. 232.

Carlson, B., 2002, "Educación y mercado del trabajo en América Latina frente a la globalización”, Revista de La CEPAL, núm. 77, pp. 1-141, disponible en https://www.cepal.org/es/ publicaciones/10828-educacion-mercado-trabajo-america-latina 
Centro de Estudios para el Desarrollo Argentino, Cenda, 2010, "La anatomía del nuevo patrón de crecimiento y la encrucijada actual. La economía argentina en el período 2002-2010”, Cara o Ceca, Buenos Aires.

Cimoli, M., 2005, Heterogeneidad estructural, asimetrías tecnológicas y crecimiento en América Latina, Cepal-BID, Santiago de Chile, disponible en https:/www.cepal.org/es/publicaciones/2799heterogeneidad-estructural-asimetrias-tecnologicas-crecimientoamerica-latina

Comisión Económica para América Latina y el Caribe, Cepal, 2010, La hora de la igualdad: brechas por cerrar, caminos por abrir, Cepal, Santiago de Chile, disponible en http://repositorio.cepal.org/ bitstream/handle/11362/13309/S2010986_es.pdf

Comisión Económica para América Latina y el Caribe, Cepal, 2014, Panorama Social de América Latina, Santiago de Chile, disponible en http://repositorio.cepal.org/bitstream/handle/11362/39965/4/ S1600175_es.pdf

Comisión Económica para América Latina y el Caribe, Cepal, 2015, Juventud: realidades y retos para un desarrollo con igualdad, disponible en http://repositorio.cepal.org/bitstream/handle/11362/38978/ S1500718_es.pdf?sequence $=4$

Comisión Económica para América Latina y el Caribe-Organización Iberoamericana de la Juventud (Cepal-OIJ), 2004, La Juventud en Iberoamérica: tendencias y urgencias, Cepal-OIJ, Santiago de Chile, disponible en http://repositorio.cepal.org/bitstream/ handle/11362/2785/S2004083_es.pdf;jsessionid=27037B7718 3754F79D6185007EB23B72? sequence $=1$

Damill, M. y R. Frenkel, 2015, "La economía bajo los Kirchner: una historia de dos lustros", en C. Gervasoni y E. Peruzzotti (compiladores), ¿Década ganada?, Editorial Debate, Buenos Aires.

Fernández Massi, M., 2014, Una mirada sectorial sobre las inserciones laborales precarias de los jóvenes en Argentina. Tiempos contingentes: inserción laboral de los jóvenes en la Argentina posneoliberal, Miño y Dávila, CEIL-PIETTE, Trabajo y Sociedad, Buenos Aires, 
disponible en http://www.minoydavila.com/media/descargables/978-84-15295-72-3.pdf

Giménez, G., 2005, "La dotación de capital humano de América Latina y el Caribe", Revista de La CEPAL, núm. 86, pp. 103-122.

Hatch, N. W. y J. H. Dyer, 2004, "Human capital and learning as a source of sustainable competitive advantage", Strategic Management Journal, vol. 25, núm. 12, pp. 1155-1178, disponible en http:// onlinelibrary.wiley.com/doi/10.1002/smj.421/epdf

Herrera, S., 2010, "La importancia de la educación en el desarrollo: la teoría del capital humano y el perfil edad - Ingresos por nivel educativo en Viedma y Carmen de Patagones, Argentina”, Revista Pilquen, vol. 12, núm. 13, pp. 1-9.

Instituto Nacional de Estadísticas y Censos, Indec, 1999, "Nuevo diseño muestral en el aglomerado Gran Buenos Aires", en Encuesta Permanente de Hogares: reformulación de la Encuesta Permanente de Hogares, Indec, Argentina.

Jacinto, C., 2004, Ante la polarización de oportunidades laborales de los jóvenes en América Latina. Un análisis de algunas propuestas recientes en la formación para el trabajo. ¿Educar para qué trabajo?: discutiendo rumbos en América Latina, La Crujía, Buenos Aires.

Katzman, R., 2000, "Notas sobre la medición de la vulnerabilidad social", $5^{\circ}$ Taller Regional La medición de la pobreza: métodos y aplicaciones (continuación) (LC/R.2026), Banco Interamericano de Desarrollo, Banco Mundial, Comisión Económica para América Latina y el Caribe, Instituto Brasilero de Defensa del Consumidor, Santiago de Chile, Aguascalientes, 6 a 8 de junio.

Maurizio, R., 2011, Trayectorias laborales de los jóvenes en Argentina: ¿Dificultades en el mercado de trabajo o carrera laboral ascendente? Cepal, Santiago de Chile, disponible en http://repositorio.cepal. org/bitstream/handle/11362/5340/1/S1100146.pdf

Mezzera, J., 1992, “Subordinación y complementariedad: el sector informal urbano en América Latina”, Crítica y Comunicación, núm. 9.

Miranda, A., A. Otero y J. Zelarayan, 2005, “Distribución de la Educación y desigualdad en el empleo: los jóvenes en la Argentina 
contemporánea", $7^{\circ}$ Congreso Nacional de Estudios del Trabajo, Asociación Argentina de Especialistas en Estudios del Trabajo, Buenos Aires, disponible en http://www.aset.org.ar/congresos/7/06002.pdf

Neffa, J. C., 2012, "La evolución de la relación salarial durante la post convertibilidad", Dosier: Les capitalismes en Amérique latine. De liéconomique au politique Revue de la régulation, disponible en http://regulation.revues.org/9695

Ocampo, J. A., 2001, "Raúl Prebisch y la agenda del desarrollo en los albores del siglo XXI", Revista de La CEPAL, núm. 75, pp. 25-40, disponible en https:/www.cepal.org/es/publicaciones/33122raul-prebisch-la-agenda-desarrollo-albores-siglo-xxi

Organización Internacional del Trabajo, OIT, 2015, Informalidad laboral en Argentina: segmentos críticos y politicas para la formalización, Oficina Internacional del Trabajo, Buenos Aires, disponible en http:// www.ilo.org/wcmsp5/groups/public/@americas/@ro-lima/@ilobuenos_aires/documents/publication/wcms_234705.pdf

Palomino, H., 2007, "La instalación de un nuevo régimen de empleo en Argentina: de la precarización a la regulación”, Revista Latinoamericana de Estudios Del Trabajo, vol. 12, núm. 19, pp. 121-144, disponible en https://dialnet.unirioja.es/servlet/ articulo? codigo $=2739420$

Paz, J., 2007, "Retornos laborales a la educación en la Argentina. Evolución y estructura actual”, Serie Documentos de Trabajo, núm. 355, Área Economía, Universidad de CEMA, disponible en https://www.researchgate.net/publication/4806616_Retornos_ laborales_a_la_educacion_en_la_Argentina_Evolucion_y_estructura_actual

Pérez, P., 2008, La inserción ocupacional de los jóvenes en un contexto de desempleo masivo. El caso argentino entre 1995 y 2003, Miño y Dávila Editores, Ceil-Piette CONICET, Buenos Aires, p. 252.

Pérez, P. E., C. Deleo y M. Fernández Massi, 2013, "Desigualdades sociales en trayectorias laborales de jóvenes en la Argentina", Revista Latinoamericana de Población, vol. 7, núm. 13, pp. 61-89, disponible en http://www.redalyc.org/pdf/3238/323830085003.pdf 
Pinto, A., 1976, "La CEPAL y el problema del progreso técnico", $E l$ Trimestre Económico, vol. 43, núm. 170, pp. 267-284, disponible en http://www.jstor.org/stable/20856551?seq=1\#page_scan_ tab_contents

Piore, M., 1975, Notes for a Theory of Labor Market Stratification, D.C. Heath, Lexington.

Piore, M. J., 1983, "Labor Market Segmentation: To What Paradigm Does It Belong?", The American Economic Review, vol. 2, núm. 73, pp. 249-253.

Prebisch, R., 1949, "El desarrollo económico de la América Latina y algunos de sus principales problemas", CEPAL-Naciones Unidas, núm. 63, disponible en http://repositorio.cepal.org/bitstream/ handle/11362/40010/1/prebisch_desarrollo_problemas.pdf

Prebisch, R., 1970, Transformación y desarrollo: la gran tarea de América Latina, Fondo de Cultura Económica, México, D. F.

Programa de las Naciones Unidas para el Desarrollo, PNUD, 2011, Aportes para el desarrollo humano en Argentina / 2011: Género en cifras: mujeres y varones en la sociedad argentina, Programa de las Naciones Unidas para el Desarrollo, Buenos Aires, disponible en http://www.unfpa.org.ar/sitio/images/stories/pdf/2015-06_ aportesdesarrollo.pdf

Reich, M. D., M. Gordon y R. C. Edwards, 1973, "Dual Labor Markets: A Theory of Labor Market Segmentation”, American Economic Review, núm. 63, pp. 359-365.

Rodríguez, O., 2001, "Prebisch: Actualidad de sus ideas básicas”, Revista de La CEPAL, núm. 75, pp. 41-52, disponible en https://www. cepal.org/publicaciones/xml/9/19319/rodriguez.pdf

Rubio, M. B. y A. Salvia, 2018, “Los jóvenes en el mercado laboral argentino bajo regímenes macroeconómicos diferentes: neoliberalismo y neodesarrollismo (1992-2014)", Revista Colombiana de Ciencias Sociales, vol. 9, núm. 1.

Rubio, B., M. Fachal y R. Robles, 2017, "Empleo, educación y desigualdad de ingresos: los jóvenes argentinos en un mercado laboral heterogéneo", Ponencia presentada en el Seminario Internacional de Desigualdad y Movilidad Social, La Plata. 
Salvia, Agustín, 2008, “Jóvenes promesas. Trabajo, educación y exclusión social de jóvenes pobres en la Argentina. Buenos Aires: Miño y Davila”, disponible en https://www.aacademica.org/agustin. salvia/87.pdf

Salvia, A., 2012, La trampa neoliberal. Un estudio sobre los cambios en la heterogeneidad estructural y la distribución del ingreso en la Argentina: 1990-2003, EUDEBA, Buenos Aires, disponible en https:// www.aacademica.org/agustin.salvia/109.pdf

Salvia A. y A. Miranda, 2003, “ ¿Trabajar, estudiar o dejar pasar el tiempo? Cambios en las condiciones de vida de los jóvenes del Gran Buenos Aires", Documentos de Trabajo. Serie Jóvenes Investigadores-1, Flacso, México.

Salvia, Agustín y Ianina Tunón, 2007, "Educación, trabajo y exclusión social en los jóvenes. Una estructura de oportunidades menos discriminatoria por sexo pero más precaria para todos. Total urbano EPH-1990-2001”, en Amalia Eguia, Juan I. Pirovani y Agustín Salvia (compiladores), Género y Trabajo: Estudios de las asimetrias intergéneros e intragéneros en áreas metropolitanas de la Argentina. 1992-2002, EDUNTREF, Buenos Aires, Argentina, disponible en https://www.aacademica.org/iigg/box/agustin.salvia/58.pdf

Salvia, A. y J. Vera, 2013, "Heterogeneidad Estructural, calidad de los empleos y niveles educativos de la fuerza de trabajo en la Argentina post reformas (2004-2007-2011)", en $11^{\circ}$ Congreso Nacional de Estudios del Trabajo, núm. 1, pp. 1-26, disponible en http:// www.aset.org.ar/2013/ponencias/p3_Salvia.pdf

Salvia, A. y J. Vera, 2015, "Las desigualdades estructurales y el efecto de la educación sobre las oportunidades de empleo pleno", en Javier Lindenboim y Agustín Salvia (compiladores), Hora de Balance. Proceso de acumulación, mercado de trabajo y bienestar. Argentina, 2002-2014, Editorial Universitaria de Buenos Aires, Buenos Aires.

Salvia, A., R. Robles y M. N. Fachal, 2017, en prensa, "Estructura sectorial del empleo, nivel educativo de la fuerza de trabajo y diferenciales de ingresos laborales en la Argentina (1992-2014)", Cuadernos de Relaciones Laborales, Universidad Complutense de Madrid, Madrid. 
Schultz, T. W., 1961, "Investment in Human Capital”, The American Economic Review, vol. 51, núm. 1, pp. 1-17, disponible en http:// la.utexas.edu/users/hcleaver/330T/350kPEESchultzInvestment HumanCapital.pdf

Terrones, M. E. y C. Calderón, 1993, "Educación, capital humano y crecimiento económico: el caso de América Latina", Economía, vol. 16, núm. 31, pp. 23-70, disponible en http://revistas.pucp. edu.pe/index.php/economia/article/view/449/441

Tokman, V., 2001, "Las relaciones entre los sectores formal e informal. Una exploración sobre su naturaleza", Economía, vol. 24, núm. 48, pp. 17-73, disponible en http://revistas.pucp.edu.pe/index. $\mathrm{php} / \mathrm{economia/article/view/847}$

Tunón, I., 2011, Juventud, Educación y Trabajo: Oportunidades de Inclusión de los Jóvenes en la Argentina (1974-2008), Tesis de doctorado, Universidad de Buenos Aires, Facultad de Ciencias Sociales, disponible en https://www.aacademica.org/ianina.tunon/48.pdf

Vera, J., 2013, “Informalidad y segmentación laboral desde la perspectiva estructuralista: una aplicación para la Argentina”, Revista Lavboratorio, Año 14, núm. 25, pp. 11-35, disponible en http:// publicaciones.sociales.uba.ar/index.php/lavboratorio/article/ download/117/104

Wainer, A. y M. Schorr, 2014, "La economía argentina en la postconvertibilidad: problemas estructurales y restricción externa”, Revista Realidad Económica, IADE, núm. 286. "La crisis mundial y sus consecuencias en América Latina”, Documento de Trabajo núm. 3, Centro de Investigación y Formación de la República Argentina, noviembre de 2009.

Weller, J., 2003, La problemática inserción laboral de los y las jóvenes, Serie Macroeconomía del Desarrollo, núm. 28, Cepal, Santiago de Chile, disponible en http://archivo.cepal.org/pdfs/2003/ S0312870.pdf

Weller, J., 2006, Los jóvenes y el empleo en América latina. Desafios y perspectivas ante el Nuevo escenario laboral, Mayol, Cepal-GTZ, Bogotá, disponible en http://repositorio.cepal.org/bitstream/handle/11362/1902/S33134W448_es.pdf?sequence 


\section{Anexo}

Tabla A.1 Desglose de los sectores y categorías económico-ocupacionales de la ocupación principal y de los ingresos provenientes de la misma.

\begin{tabular}{|c|c|c|}
\hline Sectores & $\begin{array}{l}\text { Categoría/ } \\
\text { Sector }\end{array}$ & $\begin{array}{l}\text { Operacionalización } \\
\text { y tipo de ingreso } \\
\text { de cada categoría/sector }\end{array}$ \\
\hline \multirow{2}{*}{$\begin{array}{l}\text { Sector Privado Formal } \\
\text { Actividades laborales de elevada pro- } \\
\text { ductividad y altamente integradas } \\
\text { económicamente a los procesos de } \\
\text { modernización. } \\
\text { Se las define habitualmente como } \\
\text { aquellas que conforman el mercado } \\
\text { más concentrado o estructurado. En } \\
\text { términos operativos, son ocupacio- } \\
\text { nes en establecimientos medianos o } \\
\text { grandes o actividades profesionales. }\end{array}$} & Asalariado & $\begin{array}{l}\text { Salarios como obrero o emplea- } \\
\text { do que trabaja en establecimien- } \\
\text { to privado con más de cinco } \\
\text { ocupados }\end{array}$ \\
\hline & No asalariado & $\begin{array}{l}\text { Utilidades como cuenta propia } \\
\text { profesional. Ganancias como } \\
\text { patrones profesionales o de es- } \\
\text { tablecimientos con más de cinco } \\
\text { ocupados }\end{array}$ \\
\hline \multirow{2}{*}{$\begin{array}{l}\text { Sector Privado Informal } \\
\text { Salarios como obrero o empleado } \\
\text { no profesional que trabaja en esta- } \\
\text { blecimiento privado con hasta cinco } \\
\text { ocupados. } \\
\text { Actividades laborales dominadas } \\
\text { por la baja productividad, alta rota- } \\
\text { ción de trabajadores, inestabilidad y } \\
\text { su no funcionalidad al mercado for- } \\
\text { mal o más estructurado. En términos } \\
\text { operativos, son ocupaciones en esta- } \\
\text { blecimientos pe-queños, actividades } \\
\text { de servicio domés-tico o actividades } \\
\text { independientes no profesionales. }\end{array}$} & Asalariado & $\begin{array}{l}\text { Salarios como obrero o emplea- } \\
\text { do no profesional que trabaja } \\
\text { en establecimiento privado con } \\
\text { hasta cinco ocupados. }\end{array}$ \\
\hline & No asalariado & $\begin{array}{l}\text { Utilidades como cuenta propia } \\
\text { o ayuda familiar sin calificación } \\
\text { profesional. } \\
\text { Ganacias como patrón de es- } \\
\text { tablecimiento con hasta cinco } \\
\text { empleados con calificación no } \\
\text { profesinal. } \\
\text { Ingresos como trabajador que } \\
\text { presta servicios domésticos en } \\
\text { hogares particulares. }\end{array}$ \\
\hline \begin{tabular}{|l|} 
Sector Público \\
Actividades laborales vinculadas al \\
desarrollo de la función estatal en sus \\
distintos niveles de gestión. Es decir, \\
ocupaciones en el sector público na- \\
cional, provincial o municipal.
\end{tabular} & Asalariados & $\begin{array}{l}\text { Salarios de obrero y empleado } \\
\text { ocupado en el sector público. } \\
\text { Salarios de beneficiarios de } \\
\text { programas sociales que realizan } \\
\text { contraprestación laboral para el } \\
\text { sector público. }\end{array}$ \\
\hline
\end{tabular}

Fuente: Programa Cambio Estructural y Desigualdad Social, Instituto de Investigaciones Gino Germani (IIGG)-FSC-UBA, con base en datos de EPH-Indec 
Tabla A.2 Definiciones operacionales de la precariedad y los segmentos de empleo.

\begin{tabular}{|l|}
\hline \multicolumn{1}{|c|}{ Segmento primario / Empleo pleno / Empleo regulado } \\
\hline $\begin{array}{l}\text { Incluye a los asalariados con trabajo permanente e integrados a la Seguridad Social —con } \\
\text { descuento jubilatorio-, y a los trabajadores independientes - patrones y cuenta propias- } \\
\text { que trabajan más de } 34 \text { h o trabajan menos y no desean más horas y tampoco buscan otra } \\
\text { ocupación. }\end{array}$ \\
\hline \multicolumn{1}{|c|}{ Segmento secundario / Empleo precario / Empleo no regulado } \\
\hline $\begin{array}{l}\text { Incluye a los asalariados sin jubilación, y a los trabajadores independientes — patrones o } \\
\text { cuenta propia - que estaban subocupados — menos de } 35 \mathrm{~h}-\text { y deseaban trabajar más } \\
\text { horas, o estaban subocupados y buscaban otra ocupación, o bien que trabajaban más de } 35 \\
\text { h y buscaban otra ocupación. También incluye a los no asalariados cuyo ingreso mensual } \\
\text { estaba por debajo del ingreso del primer decil de los trabajadores asalariados no registrados. }\end{array}$ \\
\hline
\end{tabular}

Fuente: Programa Cambio Estructural y Desigualdad Social, Instituto de Investigaciones Gino Germani (IIGG)-FSC-UBA, con base en datos de EPH-Indec 
Tabla A.3 Evolución de las medias de ingresos laborales horarios reales según nivel educativo y sector de inserción, respecto del total de la fuerza de trabajo ocupada, 18 a 65 años. GBA: 2004, 2007, 2012 y 2014; en pesos del $4^{\circ}$ trimestre de 2014.

\begin{tabular}{|c|c|c|c|c|c|}
\hline & & 2004 & 2007 & 2012 & 2014 \\
\hline \multirow{5}{*}{$\begin{array}{c}\text { Sector } \\
\text { Público* }\end{array}$} & Hasta secundario incompleto HSI & 28,82 & 35,62 & 39,31 & 39,42 \\
\hline & Secundario completo SC & 38,23 & 46,20 & 58,52 & 54,36 \\
\hline & Terciario y/o Universitario incompleto TUI & 40,71 & 56,30 & 59,59 & 71,49 \\
\hline & Terciario y/o Universitario completo TUC & 64,22 & 76,95 & 81,62 & 89,63 \\
\hline & Total & 46,97 & 58,58 & 68,62 & 73,41 \\
\hline \multirow{5}{*}{$\begin{array}{c}\text { Sector } \\
\text { Privado } \\
\text { Formal }\end{array}$} & Hasta secundario incompleto HSI & 26,13 & 33,97 & 36,00 & 36,50 \\
\hline & Secundario completo SC & 39,71 & 40,84 & 47,03 & 49,81 \\
\hline & Terciario y/o Universitario incompleto TUI & 53,15 & 52,75 & 55,83 & 55,09 \\
\hline & Terciario y/o Universitario completo TUC & 73,47 & 92,65 & 74,94 & 70,29 \\
\hline & Total & 44,81 & 53,02 & 52,15 & 51,49 \\
\hline \multirow{5}{*}{$\begin{array}{c}\text { Sector } \\
\text { Informal }\end{array}$} & Hasta secundario incompleto HSI & 23,64 & 26,24 & 34,86 & 29,67 \\
\hline & Secundario completo SC & 34,36 & 33,91 & 38,91 & 36,76 \\
\hline & Terciario y/o Universitario incompleto TUI & 35,88 & 48,20 & 40,75 & 41,16 \\
\hline & Terciario y/o Universitario completo TUC & 44,16 & 69,23 & 56,77 & 45,09 \\
\hline & Total & 28,89 & 33,56 & 38,18 & 34,02 \\
\hline \multirow{5}{*}{ Total } & Hasta secundario incompleto HSI & 24,78 & 29,26 & 35,44 & 32,57 \\
\hline & Secundario completo SC & 37,10 & 38,24 & 45,02 & 44,61 \\
\hline & Terciario y/o Universitario incompleto TUI & 45,34 & 51,72 & 51,95 & 52,99 \\
\hline & Terciario y/o Universitario completo TUC & 64,86 & 83,89 & 74,46 & 71,66 \\
\hline & Total & 37,49 & 44,81 & 48,61 & 46,73 \\
\hline
\end{tabular}

*Excluye empleados públicos ocupados en programas de empleo transitorio.

Fuente: Programa Cambio Estructural y Desigualdad Social, Instituto de Investigaciones Gino Germani (IIGG)-FSC-UBA, con base en datos de EPH-Indec 
Tabla A.4 Evolución de las medias de ingresos laborales horarios reales según nivel educativo y sector de inserción, respecto del total de la fuerza de trabajo ocupada joven, 18 a 29 años. GBA: 2004, 2007, 2012 y 2014; en pesos del $4^{\circ}$ trimestre de 2014.

\begin{tabular}{|c|c|c|c|c|c|}
\hline & & 2004 & 2007 & 2012 & 2014 \\
\hline \multirow{5}{*}{$\begin{array}{c}\text { Sector } \\
\text { Público* }\end{array}$} & Hasta secundario incompleto HSI & 18,00 & 20,87 & 29,11 & 28,47 \\
\hline & Secundario completo SC & 28,70 & 25,59 & 47,01 & 44,26 \\
\hline & Terciario y/o Universitario incompleto TUI & 32,98 & 46,98 & 51,45 & 45,72 \\
\hline & Terciario y/o Universitario completo TUC & 37,50 & 49,19 & 58,95 & 59,09 \\
\hline & Total & 29,37 & 38,85 & 51,13 & 45,39 \\
\hline \multirow{5}{*}{$\begin{array}{l}\text { Sector } \\
\text { Privado } \\
\text { Formal }\end{array}$} & Hasta secundario incompleto HSI & 19,90 & 25,52 & 27,84 & 29,55 \\
\hline & Secundario completo SC & 29,74 & 32,74 & 41,11 & 35,46 \\
\hline & Terciario y/o Universitario incompleto TUI & 33,42 & 43,14 & 49,78 & 47,82 \\
\hline & Terciario y/o Universitario completo TUC & 42,84 & 56,13 & 48,70 & 53,57 \\
\hline & Total & 29,91 & 37,82 & 41,05 & 39,68 \\
\hline \multirow{5}{*}{$\begin{array}{l}\text { Sector } \\
\text { Informal }\end{array}$} & Hasta secundario incompleto HSI & 17,81 & 21,04 & 27,55 & 25,94 \\
\hline & Secundario completo SC & 19,87 & 24,08 & 33,34 & 35,60 \\
\hline & Terciario y/o Universitario incompleto TUI & 29,34 & 41,78 & 40,94 & 33,30 \\
\hline & Terciario y/o Universitario completo TUC & 30,22 & 37,79 & 52,16 & 31,23 \\
\hline & Total & 21,34 & 26,70 & 33,02 & 30,43 \\
\hline \multirow{5}{*}{ Total } & Hasta secundario incompleto HSI & 18,59 & 22,59 & 27,71 & 27,52 \\
\hline & Secundario completo SC & 25,06 & 28,90 & 38,47 & 36,17 \\
\hline & Terciario y/o Universitario incompleto TUI & 32,05 & 43,14 & 47,35 & 42,52 \\
\hline & Terciario y/o Universitario completo TUC & 38,71 & 51,85 & 52,88 & 50,61 \\
\hline & Total & 26,04 & 33,23 & 38,77 & 36,35 \\
\hline
\end{tabular}

*Excluye empleados públicos ocupados en programas de empleo transitorio.

Fuente: Programa Cambio Estructural y Desigualdad Social, Instituto de Investigaciones Gino Germani (IIGG)-FSC-UBA, con base en datos de EPH-Indec 
Tabla A.5 Evolución de las medias de ingresos laborales horarios reales para varones y mujeres según nivel educativo y sector de inserción, respecto del total de la fuerza de trabajo ocupada joven -18 a 29 ańos-. GBA: 2004, 2007, 2012 y 2014; en pesos del $4^{\circ}$ trimestre de 2014 .

\begin{tabular}{|c|c|c|c|c|c|c|c|c|c|}
\hline & \multicolumn{2}{|c|}{2004} & \multicolumn{2}{|c|}{2007} & \multicolumn{2}{|c|}{2012} & \multicolumn{2}{|c|}{2014} \\
\hline & & Varón & Mujer & Varón & Mujer & Varón & Mujer & Varón & Mujer \\
\hline \multirow{5}{*}{$\begin{array}{l}\text { Sector } \\
\text { Privado } \\
\text { Formal }\end{array}$} & HSI & 19,86 & 20,35 & 25,88 & 24,51 & 28,39 & 26,93 & 30,19 & 28,82 \\
\hline & SC & 34,39 & 21,34 & 33,51 & 31,59 & 42,63 & 38,46 & 38,08 & 29,32 \\
\hline & TUI & 35,71 & 30,94 & 47,60 & 38,64 & 50,62 & 49,85 & 50,79 & 45,84 \\
\hline & TUC & 46,70 & 41,75 & 55,31 & 56,73 & 48,67 & 48,71 & 51,47 & 55,03 \\
\hline & Total & 30,22 & 29,61 & 37,72 & 38,37 & 40,41 & 42,92 & 38,91 & 41,83 \\
\hline \multirow{5}{*}{$\begin{array}{c}\text { Sector } \\
\text { Público* }\end{array}$} & HSI & 20,82 & 16,09 & 24,08 & 16,38 & 27,68 & 31,12 & 27,76 & 30,39 \\
\hline & SC & 28,98 & 27,72 & 27,81 & 23,50 & 47,52 & 44,09 & 49,47 & 33,02 \\
\hline & TUI & 37,00 & 30,09 & 63,43 & 30,42 & 59,37 & 47,26 & 58,29 & 35,73 \\
\hline & TUC & 38,86 & 36,21 & 51,83 & 48,65 & 51,21 & 62,97 & 78,32 & 56,15 \\
\hline & Total & 31,54 & 27,11 & 43,69 & 35,15 & 48,84 & 53,25 & 47,53 & 43,44 \\
\hline \multirow{5}{*}{$\begin{array}{c}\text { Sector } \\
\text { Informal }\end{array}$} & HSI & 19,02 & 15,68 & 21,21 & 20,72 & 26,28 & 31,33 & 23,09 & 34,66 \\
\hline & SC & 23,13 & 18,20 & 27,62 & 21,32 & 37,07 & 28,71 & 38,70 & 34,35 \\
\hline & TUI & 37,59 & 26,16 & 52,96 & 36,53 & 48,27 & 34,55 & 64,35 & 32,63 \\
\hline & TUC & 25,64 & 32,19 & 51,49 & 26,38 & 57,18 & 48,82 & 35,97 & 35,35 \\
\hline & Total & 22,69 & 21,04 & 29,15 & 24,87 & 33,39 & 32,65 & 34,01 & 34,07 \\
\hline \multirow{5}{*}{ Total } & HSI & 19,43 & 16,94 & 23,18 & 21,63 & 27,21 & 30,14 & 26,55 & 33,00 \\
\hline & SC & 29,29 & 19,93 & 31,17 & 26,48 & 41,16 & 34,10 & 39,23 & 32,22 \\
\hline & TUI & 36,34 & 29,11 & 50,72 & 36,92 & 50,70 & 44,39 & 56,08 & 39,87 \\
\hline & TUC & 40,46 & 38,31 & 54,17 & 51,30 & 51,10 & 54,03 & 50,21 & 52,36 \\
\hline & Total & 27,05 & 25,48 & 34,65 & 32,25 & 38,23 & 40,02 & 37,61 & 38,62 \\
\hline
\end{tabular}

*Excluye empleados públicos ocupados en programas de empleo transitorio.

Fuente: Programa Cambio Estructural y Desigualdad Social, Instituto de Investigaciones Gino Germani (IIGG)-FSC-UBA, con base en datos de EPH-Indec 